\title{
Animal Welfare and Ethics in the Collection of Fetal Blood for the Production of Fetal Bovine Serum
}

\author{
Rosemary J. Versteegen ${ }^{1}$, Jennifer Murray ${ }^{2}$ and Steven Doelger1 \\ ${ }^{1}$ International Serum Industry Association, McHenry, MD, USA; ${ }^{2}$ Life Science Group Ltd, Wilden, Bedfordshire, UK
}

doi:10.14573/altex.2101271

Serum and other blood-derived products, including fetal bovine serum (FBS), have been widely used in the research and pharmaceutical arenas for many years. The use of these materials has contributed significantly to many and varied advances in medical and veterinary health. These products continue to have an important role in research and drug development and manufacturing.

FBS has had a very specific role in the culture of mammalian cells for over 60 years. In 1954, for example, John Franklin Enders, Thomas Huckle Weller and Frederick Chapman Robbins were awarded the Nobel Prize for Physiology for their discovery of a method of growing the polio virus in monkey kidney cell cultures $^{1}$. Since then, FBS has proven to be a very useful tool for a broad spectrum of applications due to the ability of the product to support the growth of a wide range of mammalian cell types. Recently, growing concerns have been raised relating to the ethical collection of the product (van der Valk and Gstraunthaler, 2017; van der Valk et al., 2018; Weber and Wagner, 2021). This document seeks to clarify the situation and address those concerns.

It must be strongly emphasized that FBS is not collected through an individual process unrelated to other processes. It is, in fact, a by-product of the production of meat for human consumption. If it was not collected for use as a cell culture additive, this important resource would be diverted for use as pet food or for rendering. Ethical concerns surrounding the slaughter of animals for food have been widely addressed globally, and the slaughter processes have been refined to ensure that animals do not suffer within those processes (Nielsen and Hawkes, 2018; Murray, 2019). This is a highly regulated area with veterinary officers present on site at facilities worldwide to monitor activities. The Code of Professional Conduct for Veterinary Officers in every geography where FBS is collected ensures that rigorous controls are in place ${ }^{2,3}$. In addition, detailed studies have been carried out specifically to determine the potential for pain in fetuses that may be present at slaughter (AHAW et al., 2017; Mellor and Gregory, 2003). These, as well as specifics concerning the collection of fetal blood, will be reviewed here.

The sustainability of the food chain and the responsibility of society to maximize the use of these resources is now a focus of global concern. It is therefore clear that there is a moral obligation to not only consider the welfare of animals within the food chain but also to maximize the potential of these animals. Around $65 \%$ of the weight of an animal coming to slaughter will be meat and bones ${ }^{4}$. While fetal blood is almost exclusively destined to be processed into FBS, Figure 1 is a demonstration of how widely other bovine-derived materials are used within an extremely diverse spectrum of industries. It is estimated that greater than $95 \%$ of the animal is used in some way ${ }^{5}$.

The decision to slaughter an animal is complex and is dependent upon a large variety of economic factors and the differing farming methods from geography to geography. Most cattle that are slaughtered are bred and raised for meat production in a planned process of husbandry. Some animals may be sent to slaughter at different stages of their existence, dependent on a variety of factors including the availability of water or food, disease, general health issues or economic pressures. In some countries, the pregnancy of a cow is closely managed by artificial insemination, and in others pregnancy is less managed as animals are allowed to range freely. Hence, some beef cattle may come to slaughter pregnant. The dairy industry is the largest source of pregnant animals being sent to slaughter. This industry manages herd status closely, since it is the pregnant status of the animal that makes it suitable for milk production. The culling of animals required for effective herd management may be as high as $30 \%{ }^{6}$. Industry data shows that, based on the number of animals slaughtered in most geographies ${ }^{7}$ and the amount of fetal blood collected in the same area, it appears that around $8 \%$ of all animals coming to slaughter are pregnant.

\footnotetext{
1 https://www.nobelprize.org/prizes/medicine/1954/summary

2 https://www.rcvs.org.uk/setting-standards/advice-and-guidance/code-of-professional-conduct-for-veterinary-surgeons

3 https://www.avma.org/sites/default/files/resources/2014S_Resolution8_Attch1.pdf

4 http://www.thebeefsite.com/articles/759/dressing-percentage-of-slaughter-cattle/

5 https://beef2live.com/story-fun-facts-products-beef-cattle-0-104636

6 https://www.aphis.usda.gov/aphis/ourfocus/animalhealth/monitoring-and-surveillance/nahms/NAHMS_Dairy_Studies

7 https://www.indexmundi.com/agriculture/?commodity=cattle\&graph=total-slaughter
} 
PRODUCTSMADE FROM CATTLE $\frac{\text { SKIN }}{\text { gelait }}$

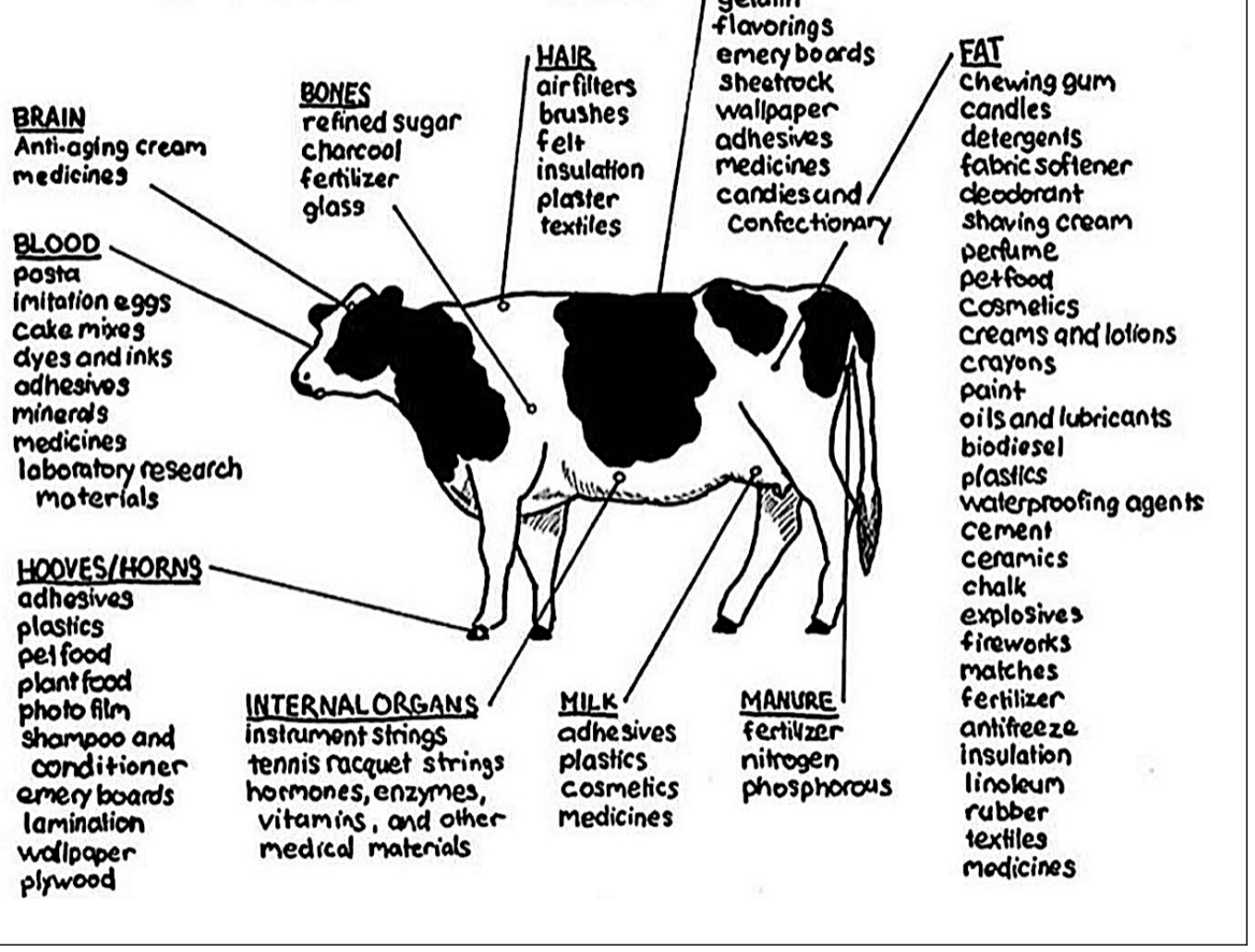

Fig. 1: Products other than meat made using bovine-derived materials

\section{Animal sentience}

The Sentience Institute 8 describes sentience as "the capacity to have positive and negative experiences, usually thought of as happiness and suffering." In recent years, various parts of the world have begun to codify the fact that animals are sentient beings, including France ${ }^{9}$, Oregon (USA) ${ }^{10}$, Quebec (Canada) ${ }^{11}$, and the Vatican ${ }^{12}$. The World Organization for Animal Health (OIE) guiding principles for animal welfare states that "the internationally recognized 'five freedoms' (freedom from hunger, thirst and malnutrition; freedom from fear and distress; freedom from physical and thermal discomfort; freedom from pain, injury and disease; and freedom to express normal patterns of behavior) provide valuable guidance in animal welfare"13. It is also clear that "the internationally recognized 'three Rs' (reduction in numbers of animals, refinement of experimental methods and replacement of animals with non-animal techniques) provide simi- lar guidance for the use of animals in science"14. The collection of FBS must therefore be performed with great attention being paid to avoidance of pain for both the fetus and the dam ${ }^{15}$.

\section{Maturation of the fetus}

Careful analysis of physical responsiveness, behavioral arousal and awareness in fetal and newborn lambs and calves provides important information on fetal maturation and consciousness (Mellor and Gregory, 2003; Mellor, 2003; Mellor et al., 2005, 2008, 2010; Mellor and Diesch, 2006). In utero, the fetus is impacted by the operation of several suppressors of both arousal and awareness. These include low levels of oxygen in the fetus, high levels of progesterone and its metabolites, warmth inside the mother, a low level of sensory input, especially tactile stimulation, and an inhibitor of behavioral arousal and breathing produced by the placenta (Mellor and Gregory, 2003). Using EEG

\footnotetext{
8 https://www.sentienceinstitute.org

9 http://www.assemblee-nationale.fr/14/amendements/1808/AN/59.asp

$10 \mathrm{https}: / /$ barkpost.com/good/oregon-court-finds-dogs-are-sentient-beings/

$11 \mathrm{http}: / /$ legisquebec.gouv.qc.ca/en/showdoc/cs/B-3.1

12 http://www.vatican.va/content/francesco/en/encyclicals/documents/papa-francesco_20150524_enciclica-laudato-si.html

13 www.oie.int/index.php?id=169\&L=0\&htmfile=chapitre_aw_introduction.htm\#article_aw_introduction.2

$14 \mathrm{https}: / /$ ec.europa.eu/environment/chemicals/lab_animals/3r/alternative_en.htm

15 https://eur-lex.europa.eu/LexUriServ/LexUriServ.do?uri=OJ:L:2010:276:0033:0079:en:PDF
} 


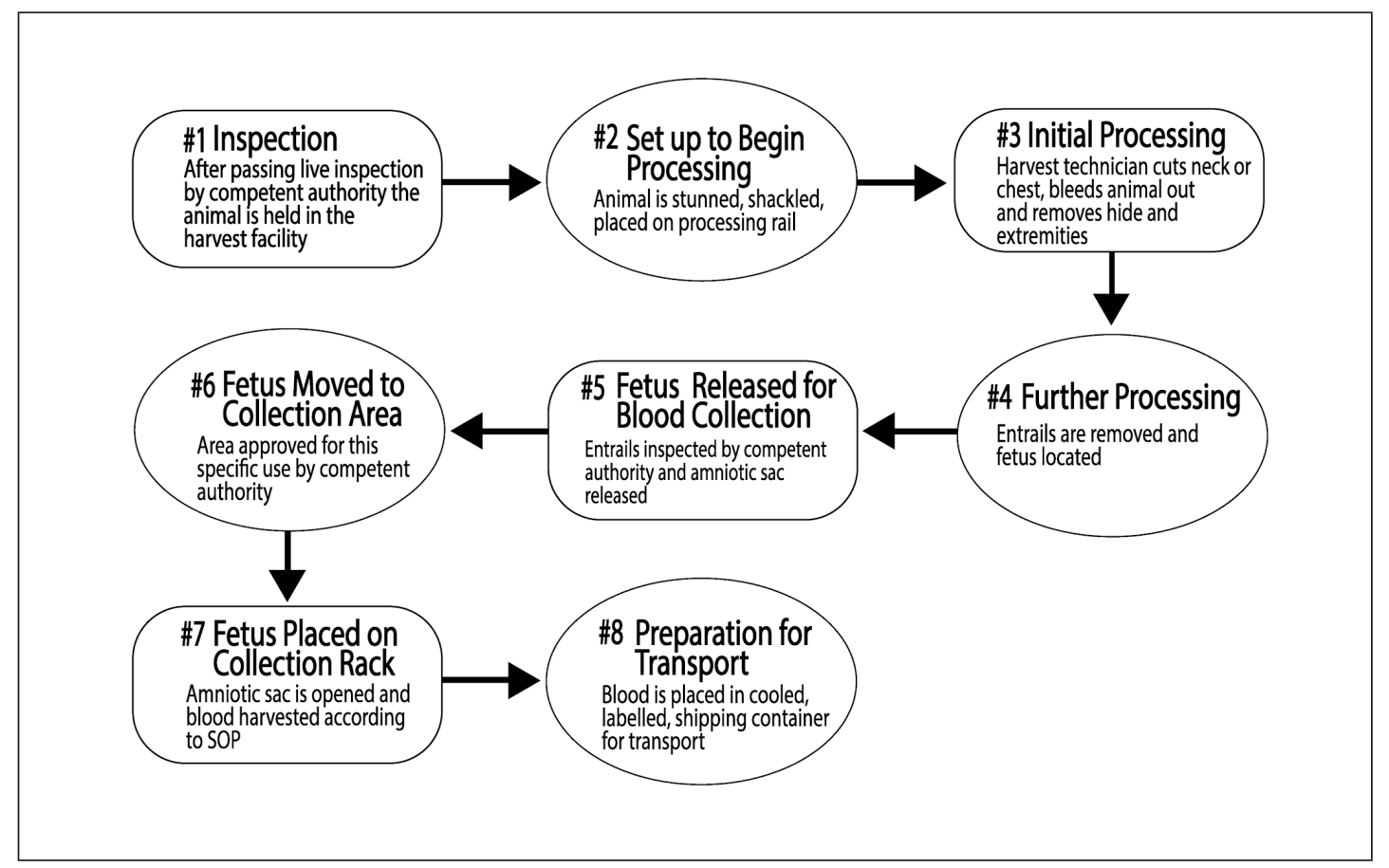

Fig. 2: Fetal bovine blood collection process flow chart

technology, it has been shown that from mid-gestation to birth, brain electrical activity of the fetus resembles that of a sleeping adult. This indicates that the fetus is not conscious and therefore cannot feel pain (Mellor and Diesch, 2006).

During pregnancy, the organs of the fetus mature slowly until three to ten days before birth when the rate of maturation accelerates due to fetal hormone changes. This maturation of fetal organs is essential for survival of the newborn. Fetuses delivered from the uterus before this time, which includes maturation of the lungs, cannot inflate their lungs with air when they try to breathe (Mellor, 2003). Therefore, fetuses delivered prematurely with immature lungs cannot increase their blood oxygen levels by breathing, and hence cannot become conscious and feel pain.

\section{Physiological changes during slaughter}

The important steps in the slaughter process with regard to the collection of fetal blood are shown in Figure 2. Within seconds of the neck or chest cut (Step 3) during the slaughter of pregnant animals, the associated catastrophic drop in blood supply to the dam's brain is paralleled by a similar drop in blood supply to all other maternal tissues, including the uterus, which prevents oxygen delivery to all fetal tissues, including the fetal brain (Mellor, 2003). The cessation of blood supply to the uterus during slaughter of pregnant ruminants causes fetal blood oxygen levels to fall and fetal blood carbon dioxide levels to rise rapidly. If the fetus remains in the uterus after slaughter, the heartbeat will ultimately cease. As can be seen in Figure 2, there are many steps after Step 3 that must occur prior to fetal blood collection. Industry and other estimates of the speed of the processing rail, and hence the time required to reach this point in the process, range from 20 to 40 minutes. As such, there is no possibility of life either inside or outside the womb. It is therefore inconceivable that a fetus could be aroused to an aware state and suffer.

\section{Fetal blood collection}

Recognizing the sentience of animals, and possibly resulting pain, the aspects of fetal blood collection that must be considered include slaughter of animals, sending pregnant animals to slaughter, transportation of pregnant animals, collection of the fetus, rescue of the fetus during slaughter, and collection of fetal blood $^{13}$.

\section{Slaughter of animals}

Guidelines and regulations exist and are universally accepted to promote humane and ethical processes for the slaughter of animals. Examples of their broad acceptance include the OIE Slaughter Guide ${ }^{16}$, EU Slaughter Regulations ${ }^{17}$, US Humane Slaughter Guidance ${ }^{18}$, and A Greener World - Animal Slaughter guidelines ${ }^{19}$. Also, each veterinary officer attending a slaughter-

\footnotetext{
16 https://bit.ly/3xdQUEO

17 https://bit.ly/3xOUTnT

18 https://animalhandling.org/producers/guidelines_audits

19 https://agreenerworld.org/wp-content/uploads/2018/05/Slaughter-Guidelines-for-Red-Meat-2017-v1.pdf
} 
house will be controlled by the Code of Practice covered by the relevant law in the country of operation.

\section{Transportation of pregnant animals}

Recent legislation outside of the USA recognizes that heavily pregnant animals should not be transported. OIE states that cows in the last 10 weeks of pregnancy should normally not be transported $^{13}$. The EU forbids the transport of pregnant females for whom $90 \%$ or more of the expected gestation period has already passed $^{20}$. Recent German legislation also reinforces this view ${ }^{21}$. These regulations result in fewer late-term cows being transported to slaughter, hence fewer fetuses in the last third of the period of their development being present. The risk of a fetus being collected that is capable of consciousness is therefore significantly reduced. It must, however, be noted that not all geographies have such regulations in place.

In practice, animals are rarely transported to slaughter in the last trimester of pregnancy unless for health reasons when the animal must be taken to the slaughterhouse nearest to the facility where the stock is held 22,23 . It is not economically viable to slaughter close-term dams since the calf is valuable and the dam will have lost significant condition. This will be reflected by a lower financial return for the farm, thereby increasing the likelihood that this will not happen.

\section{Collection of the fetus}

There is, unfortunately, a geographical disconnect in legislation in the interpretation of how an animal experiences pain. The EU considers any activity detected using an electroencephalogram (EEG) as an indication of the ability to perceive pain ${ }^{16}$, while many other geographies use consciousness of the animal as the indicator $^{13}$. The European Food Safety Authority (AHAW et al., 2017) report goes someway to addressing this comparison.

The OIE states that when fetal tissue is to be collected, the fetus should not be removed from the uterus until at least 15-20 minutes after the maternal neck or chest cut ${ }^{13}$. This will ensure that there is sufficient time for the fetus to have asphyxiated and therefore to have lost any potential for consciousness. The American Veterinary Medical Association (AVMA) states that while the animal has the capacity for sentience during the last $20-30 \%$ of gestation, while still in the uterus the fetus is unconscious ${ }^{24}$.

As previously discussed, Figure 2 shows that several steps will have occurred in the slaughter process before the fetus is removed from the uterus. These steps mean that it will routinely take a minimum of 20 minutes from the maternal neck or chest cut before the fetus is available for blood collection. This amount of time will ensure that the fetus is effectively dead and can feel no pain.

Current EU legislation deals specifically with fetal forms of mammals, based on scientific evidence showing that fetuses in the last third of the period of their development are at an increased risk of experiencing pain, suffering and distress based on continued EEG activity (AHAW et al., 2017). It has been shown, however, that the brain activity in a fetus can continue for some time after separation from the oxygenated blood flow of its mother, as mammalian neonatal neurons have protective mechanisms to help them survive the metabolic distress and low-oxygen environments (Pfisterer and Khodosevich, 2017) discussed earlier. This may help to explain the EEG activity in situations where the fetus is clearly unconscious or deceased.

\section{Rescue of fetus during slaughter}

OIE slaughter guidelines state that fetal rescue, the practice of attempting to revive fetuses found alive after evisceration of the dam, should not be attempted during normal commercial slaughter because of the potential for a negative impact on the animal after such rescue. Rather, the legislation states that if the fetus has breathed air, it be slaughtered in a painless manner ${ }^{16}$. While this regulation is in place, it is extremely unlikely to come into play as the occurrence of a live fetus being found at this point in the process has never been documented.

\section{Misconceptions}

There are also common misconceptions concerning the collection of fetal blood covered in the legislation quoted above, largely centered around continued heartbeat activity $13,15,24$. Compliance with the time requirement stated above prior to removal of the fetus from the uterus will ensure that the heart is not beating. It must be noted that in the collection process the lack of a heartbeat may require manipulation of the carcass or the use of a vacuum pump to facilitate the collection of blood.

A considerable number of scientists and researchers have misconceptions about the collection of FBS. Some think that cattle are bred purely for the collection of this material, when it is in fact a byproduct of the production of meat for human consumption. It is clear that the International Serum Industry Association (ISIA) has a duty to educate stakeholders about the reality of the process of collection, and to alleviate concerns over ethical questions. The mission of the ISIA is

- Ethics: ISIA shall establish, promote and assure compliance with uncompromised standards of excellence and ethics in the business practices of the global serum and animal derived products supply industry.

- Safety and safe use: Primary focus will be on safety and safe use of serum and animal derived products through proper origin traceability, truth in labeling, and appropriate standardization and oversight.

- Education: ISIA will work to educate stakeholders on the sci-

\footnotetext{
20 https://bit.ly/3xdQyOu

21 https://www.gesetze-im-internet.de/khfeverbg/_4.html

22 http://www.aabp.org/Resources/AABP_Guidelines/transportationguidelines-2019.pdf

23 https://www.foodstandards.gov.scot/downloads/Slaughter_of_Cattle.pdf

24 https://www.avma.org/resources-tools/avma-policies/principles-veterinary-medical-ethics-avma
} 
entific foundation of the safe use of serum and animal derived products.

ISIA members include companies covering the full range of the activities required to ensure the production and distribution of quality serum: blood collection and processing, filtration and final finishing, warehousing and distribution. Although not all FBS is traceability certified, almost all of the material used in biopharmaceutical manufacturing meets that standard.

\section{Conclusion}

All aspects of concern in the collection of fetal blood are extensively covered by significant legislation. The ISIA insists on compliance with this legislation globally. It enshrines our belief in the humane treatment of both cow and fetus throughout the process, a strong awareness of animal ethics, and the use of scientifically based information in decision-making.

Specifically, ISIA members must audit for the following as they select blood suppliers to ensure humane and ethical collection of fetal blood:

1. Compliance with animal handling and related guidelines as referenced earlier

2. Compliance with transport restrictions for heavily pregnant animals

3. Compliance with the timing of removal of the fetus from the uterus

4. Compliance with the non-resuscitation legislation.

The ISIA supports the application of the 3Rs, and many of its member companies have significant involvement in the discovery and application of new technologies and approaches to replace, reduce and refine the use of animals for scientific purposes. It is, however, clear that a move away from the use of FBS for scientific and technical applications will not reduce the number of animals used and would simply waste a valuable resource that has supported science and discovery for many years. The ISIA is happy to work with researchers to further clarify FBS questions and concerns.

\section{References}

AHAW - EFSA Panel on Animal Health and Welfare, More, S., Bicout, D. et al. (2017). Animal welfare aspects in respect of the slaughter or killing of pregnant livestock animals (cattle, pigs, sheep, goats, horses). EFSA J 15, e04782. doi:10.2903/j. efsa.2017.4782

Mellor, D. J. (2003). Guidelines for the humane slaughter of the fetuses of pregnant ruminants. Surveillance 30, 26-28. http:// www.sciquest.org.nz/node/47344

Mellor, D. J. and Gregory, N. G. (2003). Responsiveness, behavioural arousal and awareness in fetal and newborn lambs: Experimental, practical and therapeutic implications. $N \mathrm{Z} \mathrm{Vet} J$ 51, 2-13. doi:10.1080/00480169.2003.36323

Mellor, D. J., Diesch, T. J., Gunn, A. J. et al. (2005). The importance of 'awareness' for understanding fetal pain. Brain Res Brain Res Rev 49, 455-471. doi:10.1016/j.brainresrev.2005.01. 006

Mellor, D. J. and Diesch, T. J. (2006). Onset of sentience: The potential for suffering in fetal and newborn farm animals. Appl Anim Behav Sci 100, 48-57. doi:10.1016/j.applanim. 2006.04.012

Mellor, D. J., Diesch, T. J., Gunn, A. J. et al. (2008). Fetal "awareness" and "pain": What precautions should be taken to safeguard fetal welfare during experiments? AATEX J 14, Spec Issue, 79-83.

Mellor, D. J., Diesch, T. J. and Johnson, C. B. (2010). When do mammalian young become sentient? ALTEX 27, Spec Issue, 281-286. https://www.altex.org/index.php/altex/article/view/ 2214

Murray J. A. (2019). A challenging future for fetal bovine serum. BioProcess Int, 177. https://bit.ly/3deYKEG

Nielsen O. B. and Hawkes, P. W. (2019). Fetal bovine serum and the slaughter of pregnant cows: Animal welfare and ethics. BioProcess J 18. doi:10.12665/J18OA.Hawkes

Pfisterer, U. and Khodosevich, K. (2017). Neuronal survival in the brain: Neuron type-specific mechanisms. Cell Death Dis 8 , e2643. doi:10.1038/cddis.2017.64

van der Valk, J. and Gstraunthaler, G. (2017). Fetal bovine serum (FBS) - A pain in the dish? Altern Lab Anim 45, 329-332. doi:10.1177/026119291704500611

van der Valk, J., Bieback, K., Buta, C. et al. (2018). Fetal bovine serum (FBS): Past - Present - Future, ALTEX 35, 99-118. doi:10. 14573/altex.1705101

Weber, T. and Wagner, K. (2021). Replacing fetal bovine serum (FBS) in research and testing. ALTEX 38, 163-164. doi:10. 14573/altex.2012141 